\title{
Produção e indicadores fisiológicos de alface sob hidroponia com água salina
}

\author{
Dalva Paulus'; Durval Dourado Neto²; José Antônio Frizzone ${ }^{2}$; Tales M Soares ${ }^{3}$ \\ ${ }^{1}$ UTFPR-Campus Dois Vizinhos, C. Postal 157, 85660-000 Dois Vizinhos-PR; ${ }^{2}$ USP-ESALQ, Depto. Irrigação e Drena- \\ gem, 13418-900 Piracicaba-SP. ${ }^{3}$ UFRP-Depto. Tecnologia Rural, 52171-900 Recife-PE; dalvaufsmdeutch@yahoo.com.br
}

\begin{abstract}
RESUMO
O uso de água salina na produção de hortaliças constitui no momento atividade essencial, tendo em vista o aumento da demanda de água doce, tanto pela atividade agrícola quanto pelo abastecimento urbano e industrial. O objetivo do trabalho foi avaliar a produção e os indicadores fisiológicos de alface cultivada em hidroponia com a utilização de água salina. O experimento foi conduzido em ambiente protegido, em Piracicaba-SP. O delineamento experimental foi de blocos ao acaso, sendo estudados os efeitos de cinco níveis de salinidade da água de irrigação, utilizando-se $\mathrm{NaCl}$ [Condutividade elétrica (Cea): 0,42, 1,53, 3,52, 5,55 e 7,43 $\mathrm{dS} \mathrm{m}^{-1}$ ] em duas cultivares de alface (Verônica e Pira Roxa), em esquema fatorial. Foram determinadas massa fresca e seca de folhas, caule, raízes e da parte aérea; teor de nitrato, prolina e clorofila. O aumento da salinidade da água reduziu linearmente as massas fresca e seca das folhas, caule, raízes e da parte aérea. As massas fresca e seca foram 36\% e 57\% superiores na cultivar Verônica, respectivamente. A cultivar Pira Roxa apresentou maior teor de nitrato $25 \%$ (3008 $\left.\mathrm{mg} \mathrm{L}^{-1}\right)$, clorofila total 50\% $(1,46$ $\mathrm{mg} \mathrm{g}^{-1}$ massa fresca) e prolina, $71,43 \%\left(0,21 \mu \mathrm{M} \mathrm{g}^{-1}\right.$ massa fresca $\left.{ }^{-1}\right)$ em relação à Verônica, o que pode ser um mecanismo de adaptação daquela cultivar ao estresse salino. Com relação à produtividade comercial, obteve-se uma perda de 69 e $64 \%$ para as cultivares Pira Roxa e Verônica, quando se utilizou água mais salina $\left(7,43 \mathrm{dS} \mathrm{m}^{-1}\right)$. Em relação à produção de massa seca, a perda pelo uso dessa água foi de $53 \%$ e $44 \%$, respectivamente. Os resultados obtidos em sistema de cultivo hidropônico podem indicar a possibilidade do uso da água salina como alternativa para produção de hortaliças para produtores que têm disponibilidade de água salina e restrita disponibilidade de água doce, embora com redução na produtividade.
\end{abstract}

Palavras-chave: Lactuca sativa, salinidade, solução nutritiva.

\begin{abstract}
Production and physiologic indicators of lettuce grown in hydroponics with saline water
\end{abstract}

The use of saline water in the production of vegetables constitutes at the moment an essential activity, facing the rising demand of fresh water, as for the agricultural activity as for the urban and industrial supplying. This study aimed to evaluate production and physiologic indicators of lettuce in hydroponic system with the use of saline waters. The experiment was carried out in a greenhouse in the period from December 2007 to January 2008, in Piracicaba, Brazil. The experimental design was randomized blocks in factorial scheme - five salinity levels obtained with the addition of $\mathrm{NaCl}$, which resulted in different water electrical conductivity levels $\left(\mathrm{dS} \mathrm{m}^{-1}\right): 0,42,1,53,3,52$, $5,55,7,43$ - and two cultivars of lettuce - Veronica and Pira Roxa. It was determined the fresh and dry mass of leaves, stem, roots and shoot and the content of nitrate, proline and chlorophyll. The increase of water salinity reduced lineally the fresh and dry mass of leaves, stem, roots and shoot. The cv Verônica produced $36 \%$ and $57 \%$ more shoot fresh and dry mass, respectively, than Pira Roxa. The cv. Pira Roxa accumulated 25\% more nitrate (3008 $\left.\mathrm{mg} \mathrm{L}^{-1}\right)$, presented $50 \%$ more total chlorophyll (1,46 mg g-1 fresh mass) and 71,43\% more proline $\left(0,21 \mu \mathrm{M} g\right.$ fresh mass $\left.{ }^{-1}\right)$ than the cv Verônica, showing a mechanism of avoiding salinity stress. Cultivars Pira Roxa and Veronica presented loss of $69 \%$ and $64 \%$ of commercial productivity, respectively, when the most saline water $\left(7,43 \mathrm{dS} \mathrm{m}^{-1}\right)$ was used. In the other hand dry matter was reduced in $53 \%$ and $44 \%$, respectively, for cv. Pira Roxa and Verônica in the most saline water. The results obtained in this study can indicate the possibility of using saline water as an alternative for the production of vegetables, specially for growers that have saline water available but restricted fresh water, even with reduction of productivity.

Keywords: Lactuca sativa, salinity, nutrient solution.

(Recebido para publicação em 8 de janeiro de 2009; aceito em 3 de fevereiro de 2010) (Received on January 8, 2009; accepted on February 3, 2010)

$\mathrm{H}_{\mathrm{o}}^{\mathrm{a}}$ á anos vem sendo diagnosticado o problema de escassez de água no mundo, especialmente em países com grandes regiões semi-áridas como o Brasil. Diante do quadro de baixa oferta de água potável, a geração de tecnologias e pesquisa que permitam o uso de águas salinas na produção de alimentos tornam-se importantes para o cenário agrícola. $\mathrm{O}$ cultivo hidropônico representa uma alternativa ao cultivo convencional, com vantagens para o consumidor, produtor e para o meio ambiente, como obtenção de produtos de alta qualidade, encurtamento do ciclo de produção, com maior produtividade, menor gasto de água, de insumos agrícolas e de mão-de-obra. A literatura especializada em hidroponia afirma que a alface (Lactuca sativa L.) é a planta cultivada em maior escala pela Técnica do NFT (Nutrient Film Technique ou fluxo laminar de solução) devido à sua fácil adaptação ao sistema (Ohse, et al., 2001).

Águas com alto conteúdo salino podem ser utilizadas em cultivos hidropônicos, porém as plantas que se desenvolvem nessas águas estão limitadas àquelas denominadas como tolerantes e moderadamente tolerantes a sais, tais como: tomates, pepinos e alface. Rodrigues (2002) aponta a alface como cultura tolerante à salinidade, contrariando a classificação de tolerância da alface para cultivo em solo apresentada por Ayers \& 
Westcot (1999) que consideram a alface moderadamente sensível à salinidade. Em trabalhos recentes Soares (2007) concluiu que é possível utilizar águas salinas para produção de alface em hidroponia, podendo a tolerância aos sais ser superior àquela obtida em cultivos convencionais em solo.

A salinidade afeta vários processos fisiológicos e bioquímicos ao longo do ciclo de vida da planta. A resposta da planta à salinidade é complexa e variável com as condições ambientais e da planta (fase fenológica, estado nutricional), inclusive podendo variar entre cultivares de uma mesma espécie (Maas \& Hoffman, 1997). Além de reduzir o crescimento, reduz o conteúdo de clorofila em plantas sensíveis e aumenta em plantas tolerantes a salinidade (Munns, 1993). Com relação ao nitrato, existem relatos do aumento desse com os níveis mais elevados de salinidade (Chung et al., 2005).

A prolina é um aminoácido que se acumula em plantas superiores em situação de estresse (hídrico, salino, $\mathrm{SO}_{2}$ ). $\mathrm{O}$ acúmulo de prolina em plantas sob estresse pode ser conseqüência tanto do aumento na sua síntese como do decréscimo na sua degradação (Ferreira et al., 2002). O aumento dos teores de prolina pode ativar várias funções celulares como ajustamento osmótico, reserva de carbono e nitrogênio utilizado no crescimento para restabelecimento após estresse, desintoxicação do excesso de amônia, estabilizador de proteínas e membranas e eliminadores de radicais livres. A prolina está presente em pequenas quantidades nas plantas, aproximadamente entre 1 a $5 \mu \mathrm{mol} \mathrm{g}{ }^{-1}$ de massa seca e devido à sua importância no ajustamento osmótico é o composto mais estudado em plantas sob estresses abióticos (Kavi Kishor et al., 2005).

Pesquisas quanto à utilização de águas salinas no preparo da solução nutritiva e reposição da água evapotranspirada para alface justificam a importância da realização desse estudo, o que pode ser uma alternativa de renda para o agricultor que apresenta somente a opção de água salina na propriedade.

O objetivo do trabalho foi avaliar a produção e os indicadores fisiológicos de alface cultivada em hidroponia com a utilização de água salina.

\section{MATERIAL E MÉTODOS}

O experimento foi conduzido de dezembro de 2007 a janeiro de 2008 em ambiente protegido, na ESALQ em Piracicaba-SP. A casa de vegetação de $126 \mathrm{~m}^{2}$ é do tipo arco simples coberta com filme transparente de polietileno de baixa densidade com $0,10 \mathrm{~mm}$ de espessura e nas laterais por telas com $50 \%$ de sombreamento.

Foram avaliadas as cultivares Verônica de coloração verde e a Pira Roxa de coloração roxa, ambas do tipo crespa. As mudas foram produzidas em espuma fenólica e transplantadas para o berçário com sete dias, irrigadas com solução nutritiva (Furlani, 1998) diluída a 50\% e com sete dias após transplante com solução nutritiva a $100 \%$, visando sua adaptação às condições experimentais, ou seja, ao cultivo com águas salinas (Soares, 2007). Utilizou-se o sistema NFT, onde a solução nutritiva foi distribuída nos canais de cultivo numa vazão de $1,6 \mathrm{~L}$ por minuto com frequência de irrigação programada com o auxilio de temporizador para acionar a moto-bomba durante 15 min no período diurno (07:00 - 20:00 h) e $15 \mathrm{~min}$ a cada intervalo de $2 \mathrm{~h}$ no período noturno (20:00 - 07:00h).

A solução nutritiva foi conduzida por bombeamento através de uma tubulação de PVC do reservatório até a parte mais alta do canal de cultivo e retornada ao reservatório por gravidade. Para o armazenamento da solução nutritiva, na quantidade de $45 \mathrm{~L}$, foram utilizados reservatórios de polietileno com capacidade de $60 \mathrm{~L}$.

Os canais de cultivo de polipropileno tinham diâmetro comercial de $100 \mathrm{~mm}$ e comprimento de 2,8 m. Estes foram sustentados por quatro pontos de apoio de madeira instalados a uma altura média de $0,85 \mathrm{~m}$, com declividade de $3,3 \%$. O espaçamento utilizado foi de $0,3 \times 0,25$ $\mathrm{m}$ entre linhas e entre plantas.

A solução nutritiva utilizada foi baseada em Furlani (1998) com condutividade elétrica próxima a $2,00 \mathrm{dS} \mathrm{m}^{-1}$ quando composta a partir de água com baixa salinidade $\left(0,20 \mathrm{dS} \mathrm{m}^{-1}\right)$. Como o experimento foi conduzido no período de verão, optou-se em utilizar a concentração da solução nutritiva a $75 \%$.

O delineamento experimental foi de blocos ao acaso, sendo estudados os efeitos de cinco níveis de salinidade da água de irrigação, utilizando-se $\mathrm{NaCl}$ (Condutividade elétrica (Cea): 0,42, $1,53,3,52,5,55$ e $\left.7,43 \mathrm{dS} \mathrm{m}^{-1}\right)$ em duas cultivares de alface, em esquema fatorial. As quantidades de $\mathrm{NaCl}$ utilizadas nos tratamentos foram $\left(\mathrm{g} \mathrm{L}^{-1} \mathrm{de} \mathrm{NaCl}\right)$ : Testemunha $=0 ; \mathrm{T} 1=0,585 ; \mathrm{T} 3=1,755$; $\mathrm{T} 5=2,925 ; \mathrm{T} 7=4,095$.

Aos 23 dias após o transplantio foram colhidas quatro plantas centrais do perfil de cultivo, que foram separadas em parte aérea e raízes e pesadas para obtenção da massa fresca. A parte aérea e as raízes foram submetidas à pré-secagem e, posteriormente, levadas à estufa com circulação de ar à temperatura de $65^{\circ} \mathrm{C}$ para obtenção das respectivas massas secas.

Os teores de clorofila a, clorofila b e total foram determinados pelo método extrativo, metodologia modificada de Lee et al. (1987) e Moran (1982).

O teor de prolina foi determinado conforme metodologia descrita por Bates (1973).

Para avaliar o teor de nitrato na seiva da alface coletou-se a folha mais jovem completamente expandida de cada parcela. Com auxílio de uma tesoura, a nervura central dessa folha foi separada do limbo e cortada em pedaços, os quais foram prensados em uma prensa manual (esmagador de alho). O extrato foi avaliado em sensor eletrônico ('Horiba') específico para testes rápidos de nitrato.

Os resultados foram processados no programa "SAS" (SAS, Institute, 1999) para análise de variância, análise de regressão polinomial e teste de comparação de médias (Tukey a 5\% de probabilidade).

\section{RESULTADOS E DISCUSSÃO}

Durante o período de condução do experimento, as condições climáticas foram favoráveis para o desenvolvimento da alface, sendo a média das temperaturas máximas de $34^{\circ} \mathrm{C}$ e a das mínimas de 
Tabela 1. Condutividade elétrica da solução nutritiva preparada com água salina e sua média ponderada no tempo em função da salinidade da água de reposição ao longo do ciclo de cultivo (electric conductivity of the prepared nutrient solution with saline water and average obtained as a result of the salinity of the water of the replacement along the cultivation cycle). Piracicaba, ESALQ, 2008.

\begin{tabular}{|c|c|c|c|c|c|c|c|c|c|c|}
\hline \multirow{2}{*}{ Tratamento } & \multirow{2}{*}{$\begin{array}{c}\text { CEa } \\
\left(\mathrm{dS} \mathrm{m}^{-1}\right)\end{array}$} & \multicolumn{8}{|c|}{$\operatorname{CEsol}\left(\mathrm{dS} \mathrm{m}^{-1}\right)$} & \multirow{2}{*}{$\begin{array}{c}\text { Média pon- } \\
\text { derada }\left(\mathrm{dS} \mathrm{m}^{-1}\right)\end{array}$} \\
\hline & & O DAT & 4 DAT & 8 DAT & 11DAT & 13 DAT & 16 DAT & 19 DAT & 22 DAT & \\
\hline Teste & 0,42 & 1,74 & 1,77 & 1,82 & 1,68 & 1,58 & 1,49 & 1,37 & 1,28 & 1,52 \\
\hline $\mathrm{T} 1$ & 1,53 & 2,78 & 2,90 & 3,13 & 2,99 & 2,96 & 3,04 & 3,14 & 2,96 & 2,93 \\
\hline $\mathrm{T} 3$ & 3,52 & 4,87 & 5,25 & 5,71 & 5,45 & 5,63 & 5,93 & 6,23 & 6,08 & 5,67 \\
\hline T5 & 5,55 & 7,04 & 7,60 & 8,36 & 7,97 & 8,24 & 8,77 & 9,25 & 8,67 & 8,14 \\
\hline $\mathrm{T} 7$ & 7,43 & 8,98 & 9,76 & 10,82 & 10,30 & 10,66 & 11,15 & 11,76 & 11,52 & 10,64 \\
\hline
\end{tabular}

$21^{\circ} \mathrm{C}$, a radiação solar líquida incidente média de $7 \mathrm{MJ} / \mathrm{m}^{-2} \mathrm{dia}^{-1}$.

Nas condições em que o experimento foi desenvolvido, ao utilizar águas salinas no preparo da solução nutritiva e na reposição da evapotranspiração da alface, verificou-se salinização crescente nos tratamentos salinos. Para o tratamento com água não salina verificou-se redução da salinidade da solução nutritiva em decorrência do consumo de nutrientes que é superior ao acúmulo de sais dissolvidos na água (Tabela 1). Entretanto é interessante observar que a magnitude da salinização da água de maior salinidade é menor $\left(2,54 \mathrm{dS} \mathrm{m}^{-1}\right)$ que a obtida por Soares (2007) em avaliações com águas salinas em reposição à evapotranspiração de alface Verônica em NFT, onde a água de maior salinidade $\left(7,46 \mathrm{dS} \mathrm{m}^{-1}\right)$ elevou a CEsol de 2,24 para 7,07 $\mathrm{dS} \mathrm{m}^{-1} \mathrm{em} 25$ dias, o que pode ser atribuído a fatores climáticos, relacionados com a evapotranspiração da planta e características da cultivar em resposta ao estresse salino.

Crescimento e Produção - A interação entre cultivares e níveis de salinidade foi significativa $(p<0,01)$ para as variáveis analisadas. A cultivar Verônica apresentou crescimento superior à cultivar Pira Roxa de 37,71\%, 20,58\%, $35,80 \%$ para massa fresca das folhas, massa fresca do caule e massa fresca da parte aérea, respectivamente (Figura $1 \mathrm{a}, 1 \mathrm{~b}$ e $1 \mathrm{c})$. $\mathrm{O}$ aumento da salinidade da água reduziu, linearmente, a massa fresca e seca da parte aérea das cultivares, das folhas e do caule, e a massa seca das raízes e massa fresca e seca da parte aérea das cultivares em estudo. Conforme os estudos de regressão, os decréscimos relativos à água não salina $\left(0,42 \mathrm{dS} \mathrm{m}^{-1}\right)$ para cada incremento unitário de CE da água das cultivares Verônica e Pira Roxa, respectivamente, foram de $13,54 \%$ e $14,51 \%$ para massa fresca de folha; $17,79 \%$ e $19,53 \%$ para massa fresca do caule; $14,11 \%$ e $9,54 \%$ massa fresca da parte aérea.

Semelhantes declividades entre os extremos de salinidade avaliados são encontradas ao se analisar as reduções lineares das cultivares Verônica e Pira Roxa, respectivamente, para a massa seca das folhas $11 \%$ e $12 \%$; do caule $15 \%$ e $16 \% ; 11 \%$ e $7,04 \%$ para massa seca total (Figura 1d, 1e e 1g). A massa seca das raízes, por sua vez, reduziu $5,12 \%$ para a Pira Roxa, enquanto para Verônica não houve significância nas diferenças da variável analisada (Figura 1f).

Nas condições em que o experimento foi desenvolvido, as reduções lineares das massas fresca das folhas e do caule da cultivar Pira Roxa foram superiores $7 \%$ e $10 \%$ em relação à Verônica, sendo o efeito da salinidade da água mais acentuado nas variáveis de crescimento da cultivar Pira Roxa. Em trabalhos com a cultivar Verônica e em sistema hidropônico NFT, mas com águas salinas utilizadas apenas na reposição do volume consumido, Soares (2007) obteve reduções lineares para massa fresca das folhas $(2,34 \%)$, massa fresca do caule $(4,3 \%)$ e massa fresca da parte aérea $(2,27 \%)$. Segundo o autor o efeito da salinidade da água sobre o crescimento foi moderado devido aos valores de declividade terem sido baixos.

As reduções lineares obtidas no presente estudo sugerem que os íons absorvidos e transportados para a parte aérea possivelmente excederam o limite necessário ao ajustamento osmótico da planta, e desta forma acarretaram efeitos danosos ao crescimento (Flower et al., 1986).

A salinidade da água afetou a relação raiz/parte aérea, com efeito quadrático para as cultivares analisadas (Figura $1 \mathrm{~h}$ ). Em termos relativos verificou-se que as relações raiz/parte aérea foram de $0,27 \%$ e $0,24 \%$ para as cultivares Pira Roxa e Verônica, respectivamente. O estudo da massa seca da parte aérea permitiu observar a redução dessa variável com o aumento da salinidade o que condiz com o aumento da relação raiz/parte aérea; portanto, o efeito da salinidade sobre as raízes é menor que sobre a parte aérea da alface em hidroponia. Segundo Munns (1993) a redução no crescimento da parte aérea é maior do que no sistema radicular e essa resposta é comum em plantas submetidas ao estresse salino (Munns, 1993). Esse comportamento pode estar associado a um ajuste osmótico mais rápido e uma perda de turgor mais lenta das raízes, quando comparadas com a parte aérea (Shalhevet et al, 1995).

Analisando a qualidade comercial das cultivares Pira Roxa e Verônica verificou-se que as cultivares não apresentaram injúrias severas que pudessem afetar o preço de venda, portanto, toda a massa fresca foi considerada como produtividade comercial. Para fins comerciais as cultivares Pira Roxa e Verôncia apresentaram perdas de $69 \%$ e $64 \%$ respectivamente, quando se utilizou água mais salina $\left(7,43 \mathrm{dS} \mathrm{m}^{-1}\right)$. Em relação à produção de massa seca, a perda pelo uso dessa água foi de $53 \%$ e $44 \%$.

O efeito da salinidade da água sobre o crescimento da alface cultivar Pira Roxa foi superior em relação a cultivar Verônica. Além das características de 


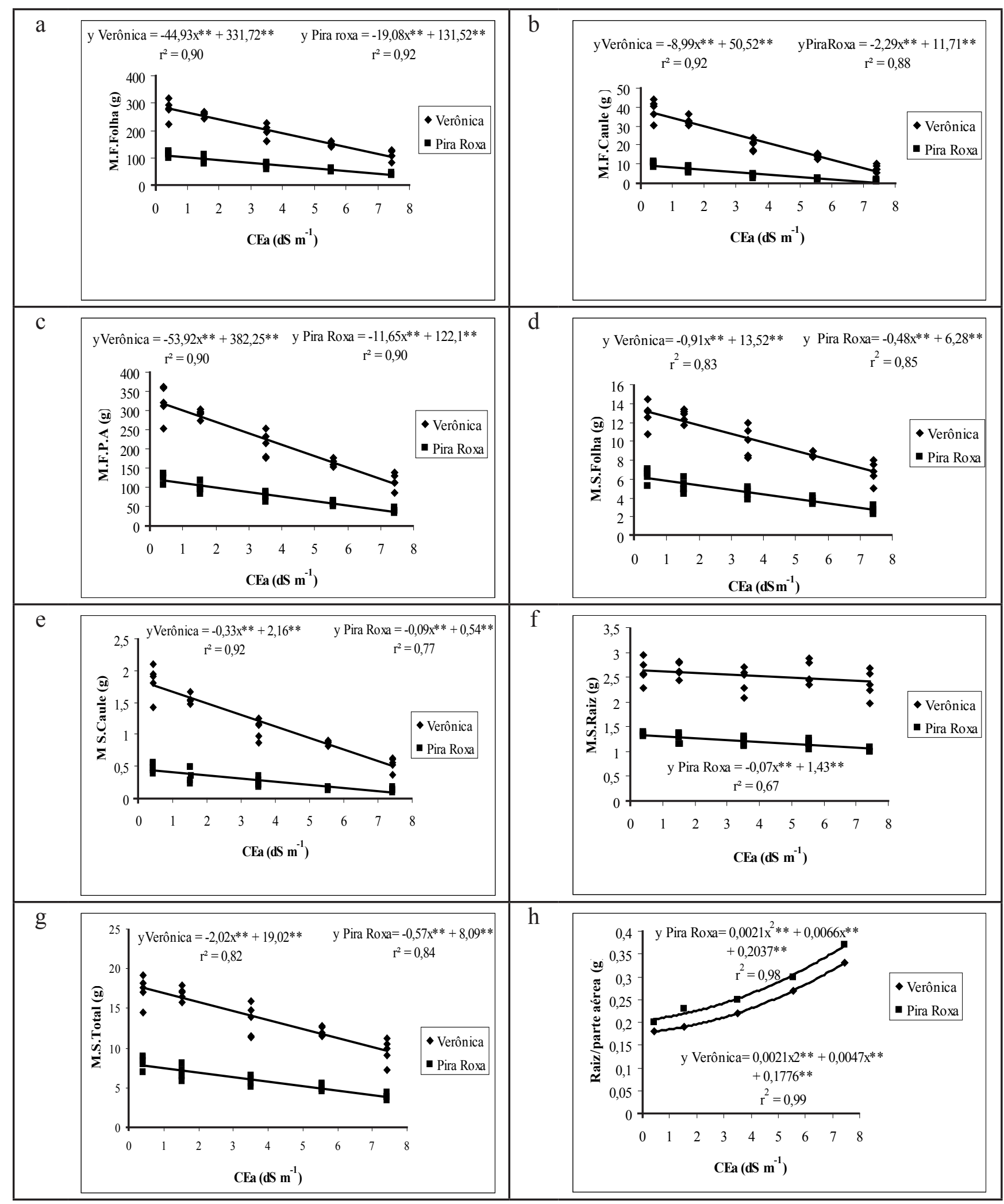

Figura 1. Massa fresca das folhas (a), do caule (b) e total (c), massa seca das folhas (d), caule (e), raízes (f), total (g) e relação raiz/parte aérea (h) de alface cultivar Verônica e Pira Roxa em função da salinidade da água ((a) leaves fresh mass, (b) stem fresh mass and (c) shoot fresh mass, (d) leaves dry mass, (e) stem dry mass, (f) root dry mass, (g) shoot dry mass and (h) root/shoot ratio obtained as a result of the salinity of the water). Piracicaba, ESALQ, 2008.

** significativo a $1 \%$ de probabilidade pelo teste $\mathrm{F}$ (** significant at $1 \%$ probability through the $\mathrm{F}$ test). 


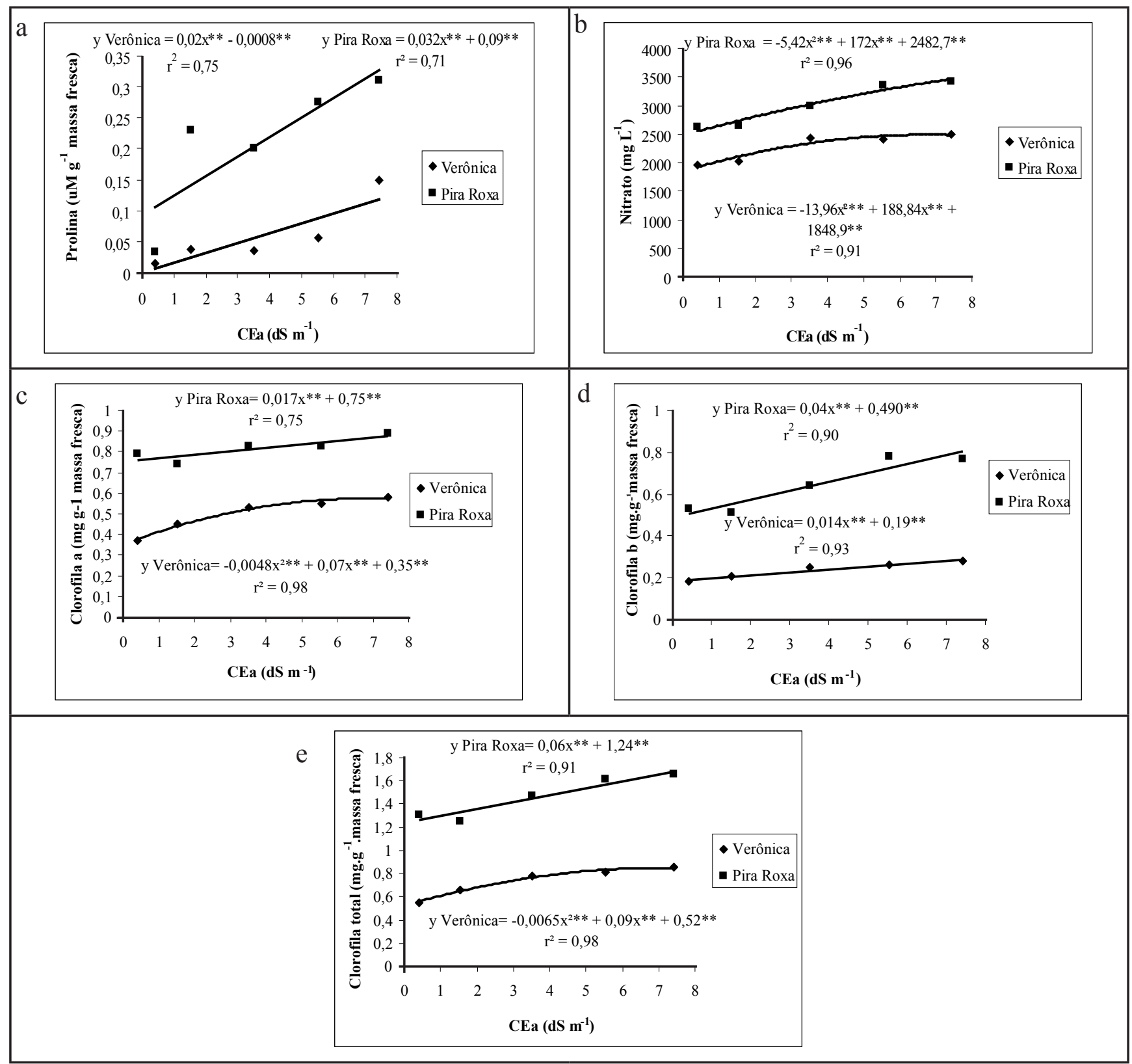

Figura 2. Teor de prolina (a), nitrato (b), clorofila a (c), clorofila b (d), clorofila total (e) de alface cultivar Verônica e Pira Roxa em função da salinidade da água (contents of proline (a); nitrate (b); chlorophyll a (c), chlorophyll b (d), total chlorophyll (E) of lettuce cultivate Verônica and Pira Roxa under salinity). Piracicaba, ESALQ, 2008.

**significativo a $1 \%$ de probabilidade pelo teste $\mathrm{F}$ (**significant at $1 \%$ probability through the $\mathrm{F}$ test).

cada cultivar, em resposta aos níveis de salinidade, as condições climáticas que ditam o consumo de água estão relacionadas com o potencial osmótico de cada cultivar em estudo. De acordo com Soares (2007) a resposta da planta à salinidade fica muito dependente das condições climáticas que ditam o consumo de água. Os dados de produção obtidos no presente trabalho não indicam maior viabilidade econômica da utilização de água salina, mas o número de plantas produzidas com valor comercial equivalente. Por outro lado, se for analisar o insumo água salina no contexto custo oportunidade, que os agricultores estão incorrendo por não utilizar água salina no sistema de produção, seja por falta de informação ou conhecimento da viabilidade da utilização dessas.

Teor de prolina - Foi significativo o efeito entre salinidade da água e cultivares sobre os teores de prolina. O valor médio de prolina da Pira Roxa foi $71,43 \%\left(0,21 \mu \mathrm{M}\right.$ g massa fresca $\left.a^{-1}\right)$ superior em relação a Verônica $(0,06 \mu \mathrm{M}$ $\mathrm{g}$ massa fresca $\left.{ }^{-1}\right)$. O efeito da salinidade da água sobre o teor de prolina das cultivares de alface foi linear (Figura 2a).

Resultados semelhantes foram obtidos por Passos (2001) com plântulas de graviola (Annona muricata L.) e pinha (Annona squamosa L.) em hidroponia, com diferentes concentrações salinas, onde o autor cita que a presença de prolina nas folhas é um indicativo de 
estresse em ambas espécies submetidas aos tratamentos de maiores concentrações de $\mathrm{NaCl}$ (300 e $500 \mathrm{mmol} \mathrm{L}^{-1}$ de $\mathrm{NaCl}$ ).

$\mathrm{O}$ incremento no teor de prolina parece ter várias funções, primeiramente, a de não permitir o acúmulo de $\mathrm{NH}_{4}^{+}$, composto muito tóxico por ser desacoplador da produção de ATP na fotofosforilação e fosforilação oxidativa. Também, a prolina tem a propriedade de proporcionar ajuste osmótico sem causar injúria aos tecidos em comparação ao efetuado por íons. Plantas de milho respondem à salinização pela manutenção de maiores concentrações de sacarose e prolina, visto que o nível de prolina aumenta com a salinização e com o tempo de exposição das plantas ao sal, sugerindo um papel protetor da prolina (Rodríguez et al., 1997). Nas condições em que o experimento foi desenvolvido, verificou-se que o acúmulo de prolina pode ser considerado indicador fisiológico em função do aumento da salinidade.

Teor de nitrato - Foi afetado pela salinidade da água da solução nutritiva, sendo quadrático o efeito dos estudos de regressão (Figura 2b). O teor de nitrato foi superior em 25\% para Pira Roxa (3008 $\left.\mathrm{mg} \mathrm{L}^{-1}\right)$ em relação à Verônica (2264 $\left.\mathrm{mg} \mathrm{L}^{-1}\right)$. Os menores níveis de nitrato $\left(1960 \mathrm{mg} \mathrm{kg}^{-1}\right.$ e $2620 \mathrm{mg} \mathrm{kg}^{-1} \mathrm{de}$ massa de matéria fresca) da Verônica e Pira Roxa, respectivamente, foram relacionados à condutividade elétrica de $0,43 \mathrm{dS} \mathrm{m}^{-1}$, aumentando a salinidade da água para 7,43 $\mathrm{dS} \mathrm{m}^{-1}$. O teor foliar de nitrato aumentou para $2500 \mathrm{mg} \mathrm{kg}^{-1} \mathrm{e}$ $3420 \mathrm{mg} \mathrm{kg}^{-1}$ para as cultivares Verônica e Pira Roxa.

Os níveis mais elevados de salinidade apresentaram tendência de aumento de nitrato foliar. Esses resultados podem ser explicados pela alta taxa de produção de massa fresca nos tratamentos submetidos às menores $\mathrm{CE}$, uma vez que, de acordo com Krohn et al. (2003), as folhas mais jovens acumulam mais nitrato que as maduras. Segundo Soares (2007) esses resultados podem ser explicados em função da alta taxa de produção de fitomassa nos tratamentos submetidos às menores CE. A tendência do aumento do teor de nitrato com os níveis mais elevados de salinidade pode ser explicada pelo ajuste osmótico para que a planta consiga absorver água quando submetida a condições de baixo potencial total de água (Chung et al., 2005).

Por outro lado, Miceli et al. (2003), em trabalhos com as cultivares de alface Ballerina e Severus em sistema hidropônico, constataram que aumentando a salinidade da solução nutritiva de 1,6 para 4,6 dS m ${ }^{-1}$ com adição de $\mathrm{NaCl}$, o teor de nitrato das folhas diminuiu de $2218 \mathrm{mg} \mathrm{kg}^{-1}$ para $1634 \mathrm{mg} \mathrm{kg}^{-1}$ de massa da matéria fresca.

Embora no Brasil não exista legislação específica que regularmente os teores máximos permitidos de nitrato em vegetais, os teores de nitrato obtidos encontram-se abaixo do limite máximo permitido pela comunidade européia que estabeleceu limites máximos tolerados de 3500 a $4500 \mathrm{mg}$ de $\mathrm{NO}_{3}^{-} \mathrm{kg}^{-1}$ de massa fresca para cultivo de inverno e $2500 \mathrm{mg}$ de $\mathrm{NO}_{3}{ }^{-} \mathrm{kg}^{-1}$ de massa fresca para cultivos de verão (Van Der Boon et al., 1990).

Teor de clorofila - Os teores de clorofila a, clorofila b e clorofila total apresentaram efeito linear para as cultivares em estudo (Figura 2c, 2d e 2e). O teor de clorofila total da cultivar Pira Roxa foi superior $50 \%\left(1,46 \mathrm{mg} \mathrm{g}^{-1}\right.$ massa fresca) em relação à Verônica $(0,73 \mathrm{mg}$ $\mathrm{g}^{-1}$ massa fresca). Os resultados do teor de clorofila nos níveis de salinidade mais elevados nas cultivares de alface, estão de acordo com a classificação de Rodrigues (2002) que considera a alface como tolerante à salinidade. Segundo Munns (1993) o teor de clorofila aumenta com os níveis de salinidade em espécies tolerantes e diminui em espécies sensíveis como tomate, soja e pera.

Jamil et al. (2007), analisando o estresse salino na cultura do rabanete (Raphanus sativus L.) com adição de $\mathrm{NaCl}$ na solução nutritiva verificaram que os níveis de salinidade 9,4 e 14,1 $\mathrm{dS} \mathrm{m} \mathrm{m}^{-1}$ reduziram em $39 \%$ e $59 \%$ o teor de clorofila. Os autores afirmam que o estresse salino ocasiona a destruição da estrutura do cloroplasto devido à degradação da enzima clorofilase. No presente estudo o teor de clorofila pode ser explicado por uma série de fatores como composição e concentração de sais, a duração do estresse e as diferenças entre genótipos. Ressalta-se outro fator importante como precocidade da alface e menor tempo de exposição aos sais em hidroponia, que ajudam a diminuir os efeitos da salinidade.

Os resultados obtidos em sistema de cultivo NFT podem indicar a possibilidade do uso da água salina como alternativa para produção de hortaliças para produtores que tenham disponibilidade de água salina e restrita disponibilidade de água doce, porém com redução de produtividade.

\section{REFERÊNCIAS}

AYERS RS; WESTCOT DW. 1999. A qualidade da água na agricultura. Tradução de GHEYI HR; MEDEIROS JF; DAMASCENO FAV. 2.ed. Campina Grande: UFPB. 153 p. (Estudos FAO. Irrigação e Drenagem, 29 revisado).

BATES LS; WALDREN RP; TEARE ID. 1973. Rapid determination of free proline for water stress studies. Plant and Soil 39: 205-207.

CHUNG JB; JIN SJ; CHO HJ. 2005. Low water potential in saline soils enhances nitrate accumulation of lettuce. Communications in Soil Science and Plant Analysis 36: 1773 1785.

FERREIRA VM; MAGALHÃES PC; DURÃES FOM; OLIVEIRAS LEM; PURCINO AAC. 2002. Metabolismo do nitrogênio associado à deficiência hídrica e sua recuperação em genótipos de milho. Ciência Rural 32: 1317.

FLOWER TJ; HAJIBAGHERI MA; CHIPSON NJW. 1986. The mechanism of salt tolelance in halophytes. Annual Review of Plant Physiology 28: 89-121.

FURLANI PR. 1998. Instruções para o cultivo de hortaliças de folhas pela técnica hidroponia NFT. Campinas: Instituto Agronômico. 30p. (Boletim técnico 168).

JAMIL M; REHMAN S; LEE KJ; KIM JM; KIM HS; RHA ES. 2007. Salinity reduced growth PS2 photochemistry and chlorophyll content radish. Scientia Agricola 64: 111-118.

KAVI KISHOR PB; SANGAM S; AMRUTHA RN; SRI LAXMI P; NAIDU KR; RAO KRS; RAO S; REDDY KJ; THERIAPPAN P; SREENIVASULU N. 2005. Regulation of proline biosynthesis, degradation, uptake and transport in higher plants: Its implications in plant growth and abiotic stress tolerance. Current Science 88: 424-438.

KROHN NG; MISSIO RF; ORTOLAN ML; BURIN A; STEINMACHER DA; LOPES MC. 2003. Teores de nitrato em folhas de alface em função do horário de coleta e do tipo de folha amostrada. Horticultura Brasileira 21: 216-219.

LEE DW; BRAMMEIER S; SMITH AP. 1987. The selective advantages of anthocyanins in developing leaves of mango and cacao. Biotropica 19: 40-49.

MAAS EV; HOFFMAN GJ. 1997. Crop salt tolerance - current assessment. Journal of 
Irrigation and Drainage Division 103: 115134.

MICELI A; MONCADA A; D'ANNA F. 2003. Effect of salt stress in lettuce cultivation. Acta Horticulturae 609: 371-375.

MORAN R. 1982. Formulae for determination of Chlorophyllous pigments extracted with N,N'-dimethylformamide. Plant Physiology 69: 1376-1381.

MUNNS R. 1993. Physiological processes limiting plant growth in saline soil: some dogmas and hypothese. Plant, Cell and Environment 16: 15-24.

OHSE S; DOURADO NETO D; MANFRON PA; SANTOS OS. 2001. Qualidade de cultivares de alface produzidas em hidroponia. Scientia Agrícola 58: 181-185.
PASSOS VM. 2001. Alterações fisiológicas e anatômicas em plântulas de Annona muricata L. (graviola) e Annona squamosa L. (pinha) submetidas a estresse salino. Feira de Santana: Universidade Estadual de Feira de Santana. 53p (Tese mestrado).

RODRIGUES LRF. 2002. Técnicas de cultivo hidropônico e de controle ambiental no manejo de pragas, doenças e nutrição vegetal em ambiente protegido. Jaboticabal: FUNEP. $762 \mathrm{p}$.

RODRÍGUEZ HG; ROBERTS JKM; JORDAN WR; DREW MC. 1997. Growth, water relation, and accumulation of organic and inorganic solutes in roots of maize seedlings during salt stress. Plant Physiology 113: 881-893.
SAS INSTITUTE. 1999. SAS: user's guide statistics: version 8.0 edition. Cary. 956 p.

SHALHEVET J; HUCK M.G.; SCHROEDER BP. 1995. Root and shoot growth responses to salinity in maize and soybean. Agronomy Journal 87: 512-516.

SOARES TM. 2007. Utilização de águas salobras no cultivo da alface em sistema hidropônico NFT com alternativa agrícola condizente ao semi-árido brasileiro. Piracicaba: USPESALQ. 267p (Tese doutorado).

VAN DER BOON J; STEENHUIZEN JW; STEINGRÖVER EG. 1990. Growth and nitrate concentration of lettuce as affected by nitrogen and chloride concentration, $\mathrm{NH}_{4+} /$

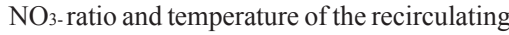
nutrient solution. Journal of Horticultural Science 65: 309-321. 